\title{
Una desconocida comedia mexicana del siglo XVII
}

A historia del teatro colonial se ha enriquecido considerablemente en estos últimos años. Estudiosos de varios países han sacado a luz muy variadas noticias sobre representaciones, autores e intérpretes, y han dado a la imprenta ediciones de obras raras, de mariuscritos sólo conocidos del especialista y, en algunos casos, de obras totalmente desconocidas. Muy pocas veces, empero, se ha tenido la fortuna de exhumar una comedia que, a más de completamente ignorada, sea de la antigüedad y del valor literario de la que a continuación daremos a conocer.

Es autor de dicha comedia el padre Matías de Bocanegra (16121668), uno de los excepcionales imitadores de Góngora cuya fama no ha sufrido empaño con las vicisitudes del tiempo. No obstante su reputación como uno de los mejores poetas americanos de su época, casi todo cuanto de su vida se sabe es lo que consignó Beristáin en la monumental Biblioteca hispano americana setentrional; es decir, que

nació en la Puebla de los Angeles a principios del siglo xvir, y fué uno de los jesuítas de la provincia de México de más vivo ingenio, y de más instrucción en las letras humanas y en las ciencias sagradas y muy estimado de los virreyes y obispos de la Nueva España. 1

A esos datos sólo se han logrado añadir las fechas de su nacimiento y muerte (1612-1675) y el año en que entró de religioso (1628), ${ }^{2}$ así como alguno que otro pormenor sobre st1s actividades eclesiásticas como, por ejemplo, su participación en el notorio proceso que la Inquisición siguió a Guillén de Lampart. ${ }^{3}$ 
Su obra es mejor conocida. Hay noticias de que publicó los siguientes trabajos: Viaje por tierra y mar del... Marqués de Villena (1640), Teatro jerárquico de la luz... que la ciudad de México erigió ... al Conde de Salvatierra (1642), Sermón a la solemne colocación de la Santa Cruz de piedra... [en la] Iglesia Catedral (1648), Sermón de la publicación de la Bula de la Santa Cruzada (1649), Relación del Auto general de la fe celebrado... en la muy noble y muy leal ciudad de México ... 16 de abril de 1649, y algunos dictámenes, elogios, aprobaciones y censuras. ${ }^{4}$ Los trabajos citados, de escaso interés para el lector moderno, no le darían en la historia de nuestras letras otro sitio que el correspondiente a un obscuro escritor colonial. La obra que le valió inmediata nombradía y que, manteniéndola a través del tiempo, le ha salvado del olvido, es su Canción a la vista de un desengaño.

Conviene que puntualicemos la fortuna de esta composición. En los siglos XVII y xviIr circuló en numerosas reimpresiones y fué, además, imitadísima. La más antigua de las imitaciones conocidas es la que hizo en 1652 Bartolomé Fernández Talón. Y a fines del siglo xvin la emularon, entre otros, el padre Juan de Arriola, Francisco José de Soria, José Manuel Colón Machado, Tomás Cayetano Ochoa y Manuel Valdés, impresor este último de la Gaceta de México de 1784 hasta 1807. Estas imitaciones tuvieron, igual que el original, gran difusión, imprimiéndose algunas de ellas varias veces. ${ }^{5}$ En los siglos xIX y xx tampoco le ha faltado admiradores. Al contrario, a más de considerarse, por su alto valor antológico, una de las cien mejores poesías líricas mexicanas, ${ }^{6}$ ha merecido constantes elogios de la crítica más seria. Así, Pimentel, en 1885, señala su “carácter moral y filosófico ..., imágenes graciosas ... toques atrevidos ... y sentimientos bien expresados." 7 Menéndez y Pelayo, en 1911, la consigna como "obra no despreciable, así por la fluidez de los versos como por la delicadeza del sentido místico." 8 Julio Jiménez Rueda alaba su "noble lirismo y... suave inspiración" ${ }^{9}$ y Carlos González Peña, tal vez bordeando ya lo hiperbólico, estima que dicha canción "está muy por encima de cuanto se escribió en su tiempo". ${ }^{10}$

Si la labor en prosa y la obra lírica de Bocanegra son conocidas, su teatro ha estado cubierto por un manto que en vano se ha tratado de rasgar. No hay de él la menor noticia en las bibliografías de 
Beristáin y de Medina, ni en la de adiciones a esta última de González de Cossío, ${ }^{11}$ ni tampoco en las citadas obras de Pimentel, Menéndez y Pelayo, Jiménez Rueda y González Peña. Es, ya en 1933, cuando Francisco Monterde, en su admirable Bibliografía del teatro en México, consigna que el licenciado Francisco Pérez Salazar decía poseer una comedia inédita de Bocanegra. ${ }^{12}$ Pero siete años después, en una nota en la Revista de literatura mexicana, que dirigía Antonio Castro Leal, se ofrece resarcir al que devolviera el manuscrito "de la comedia en verso de Matías Bocanegra", ya que el manuscrito de Pérez Salazar se había extraviado entre los papeles dejados por Nicolás Rangel, a quien su dueño se lo había prestado. ${ }^{13} \mathrm{La}$ comedia pasaba, pues, del estado de aserción no comprobada al de documento perdido.

Por otra parte, hacia 1949 halló Jiménez Rueda, entre algunos papeles sin encuadernar conservados en el Archivo General de la Nación, el manuscrito de una pieza a la que faitan las primeras páginas y que, por sus versos finales, se deduce se tituló Sufrir para merecer. La circunstancia de que entre aquellos papeles se encontraran versiones de la Canción a la vista de un desengaño llevó a pensar al ilustre investigador que dichos papeles probablemente pertenecieran a Bocanegra, y de ahí la posibilidad de atribuir dicha pieza a nuestro autor. ${ }^{14}$ Ahora bien, los que conocen con cuanta frecuencia el hallarse copia de una obra entre los manuscritos de un autor ha llevado a erróneas atribuciones, ${ }^{15}$ aprobarán el buen juicio demostrado por Jiménez Rueda al no hacer una atribución categórica, muy especialmente en un caso en que, como éste, la base para la adjudicación es haberse hallado junto a la pieza una versión de obra tan copiada y tan imitada como la Canción a la vista de un desengaño. Además, la lectura de Sufrir para merecer deja la fuerte impresión de que es obra posterior al siglo Xvir. Y si se la compara con lo que aqui se ha de citar de la comedia aparecida bajo el nombre de Bocanegra, se llegará al convencimiento de que difícilmente pudo ser autor de aquélla el sabio jesuíta mexicano. ${ }^{\mathbf{1 6}}$

Es, pues, la ignorada pieza que ahora damos a conocer la única que hasta el presente se ha hallado de Bocanegra. Se titula $\mathrm{Co}$ media de San Francisco de Borja y fué impresa en México, bajo el nombre de su autor, en 1641. Su existencia, empero, ha pasado inadvertida debido a un singular problema bibliográfico. Ya hemos 
indicado que en 1640 publicó Bocanegra una obra cuyo título completo es el siguiente:

Viaje de tierra, $y$ mar, feliz por mar, y tierra, que hizo el Excellentissimo señor Marques de Villena mi señor, yendo por Virrey, y Capitan General de la Nueva España en la flota que embió su Magestad este año de mil y seiscientos y quarenta, siendo General della Roque Centeno, y Ordoñez: su almirante Iuan de Campos. Dirigido a don Ioseph Lopez Pacheco, Conde de Santistevan de Gormaz mi señor. Con licencia del Excellentissimo Señor Virrey desta Nueva España. Impresso en Mexico: En la Imprenta de Iuan Ruyz. Año de 1640.17

Pero lo que escapó a las diligentes búsquedas de Medina y otros bibliógrafos fué que se hizo una nueva edición de dicha obra al año siguiente, y que ésta difiere considerablemente de la primera. E1 título de esta otra edición es como sigue:

Viage por tierra, y mar del excellentissimo señor don Diego Lopez Pacheco i Bobadilla, Marques de Villena, i Moia, y Duque de Escalona, \&c. Aplavsos, y festejos a sv venida por Virrei desta Nueva España. Al excellentissimo señor don Gaspar de Guzman, Conde Duque de Olivares, Duque de San Lucar la Maior, \&c. Dedicado por el Collegio Mexicano de la Compaña de Iesvs.

La portada carece de pie de imprenta. Pero aparecen consignados el nombre del impresor y la fecha de publicación en el colofón. Dice el colofón:

En México, en la Imprenta de Francisco Robledo, impressor del Secreto Officio: Por Iuan Fernández de Escobar. Año de 1641 .

De esta edición, que consta de 90 hojas numeradas, ocupa la comedia el espacio comprendido de la hoja 53 , recto, a la 83 verso. Continúa en la 84 una descripción de la representación y las coplas del tocotín que se cantaron como fin de fiesta. $Y$ se encabeza dicha comedia, en la 53, de manera que no queda el más ligero asomo de duda de la paternidad de la obra. Dice textualmente:

Comedia de San Francisco de Borja a la feliz venida del excellentíssimo señor Marqués de Villena, Virrei desta Nueua España. Compuesta por el padre Mathias de Bocanegra, de la Compañía de Iesus. 
Resuelto el problema bibliográfico, pasemos a considerar la comedia misma, y empecemos puntualizando su propósito y contenido. Se trata de una comedia hagiográfica que representaron los alumnos del Colegio de San Pedro y San Pablo, en ocasión de la visita del referido virrey al plantel de la compañía. Sabido, además, que San Francisco de Borja (1510-1572), tercer general de la orden ignaciana, fué, antes de abrazar el estado religioso, Duque de Gandia, grande de España y Virrey de Cataluña, se verá cuán apropiados resultan los versos del romance con que, al terminar la pieza, se resume y dedica el festejo:

\author{
Compañia. \\ Si el Duque de Gandia, \\ huyendo de los faustos \\ del mundo, le ha acogido \\ debajo de mi manto, \\ su lustre se ennoblece, \\ $y$ con él me honro tanto, \\ que son mis pequeñeces, \\ con él, blasones sacros. \\ Si desde España Borja \\ a México ha enviado \\ mis hijos, a él le debe \\ la gloria de gozarlos. \\ $Y$ porque a Borja estimo \\ con tan estrechos lazos \\ de amor, su conversión \\ a un príncipe consagro, \\ que en México ha querido \\ dar honra a mis teatros. \\ A un duque le dedico \\ de un duque los extraños \\ prodigios, que en España \\ viven tan admirados. \\ Con un grande he querido, \\ hoy, grande, celebraros, \\ $y$ que un virrey a otro \\ of rezca mis aplausos. \\ $\mathrm{Si}$ en este reino todos \\ su amor os han mostrado, \\ mi amor os muestro yo \\ con cuanto soy y valgo. \\ Séais tan bienvenido \\ cual fuisteis deseado,
}




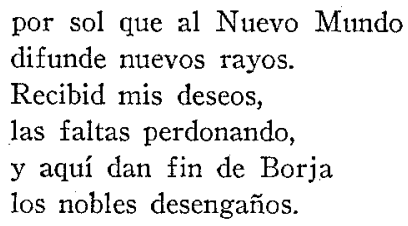

Cumplimentar al Virrey es, pues, el propósito inmediato de la comedia. $\mathrm{Y}$ evocar los nobles desengaños de Borja, ante la inexorable visita de la muerte, su tema central. Es el mismo tema, por tanto, que ocasiona las meditaciones del religioso en la Canción a la vista de un desengaño. ${ }^{18}$

La estructura de la pieza sigue el patrón, establecido por Lope y sus continuadores, de combinar en las comedias de santos elementos históricos con lances imaginados. En esta comedia tenemos, pues, una serie de episodios de indudable historicidad, interrumpidos por los inventados avances amorosos de dos damas, Belisa y Flora, enamoradas ambas del apuesto Duque, y burladas por las tretas del gracioso, Sansón. Que Belisa represente la Hermosura, Flora la Vanidad, y que aparezca momentáneamente la Virtud, para anunciarles que no tendrán éxito, son sólo un ligero velo alegórico que no impide que las dos damas sean muy de carne y hueso, y que una de ellas, en su deseo de acercarse al Duque, llegue a disfrazarse de paje y dé con ello ocasión a una típica escena de comedia de enredo. Y el gracioso, Sansón, sabihondo a veces, a veces pusilánime, pero siempre ingenioso y locuaz, viene a suplir la vena humorística en muchas de las escenas añadidas al tejido hagiográfico. ${ }^{19}$

Un resumen del argumento vendrá a perfilar la manera en que se entremezclan los planos y, a la vez, nos servirá para sustentar algunas consideraciones que hemos de hacer más adelante.

El acto primero se abre con una escena de caza. Dialogan el Duque de Gandía y su lacayo, Sansón, en diáfanas redondillas en las cuales quedan evidenciadas la nobleza de ánimo del señor y la actitud apicarada del criado. Sale entonces otro de los cazadores, Carlos V, y el diálogo se eleva a consideraciones de alto gobierno, pensamientos que Sansón comenta acentuando el lado jovial. Vanse éstos y sale a escena la Emperatriz, con doña Leonor de Castro, esposa de Borja, y nárrale la Emperatriz el sueño que presagia su próxima muerte. Reúnense ambos grupos. Carlos Quinto concede 
a su fiel vasallo honores y títulos, haciéndolo Marqués de Lombay, Comendador de Santiago, Caballerizo Mayor de la Emperatriz y Virrey de Cataluña. $\mathrm{Y}$ termina la escena en un clima ominoso al confesar la Reina su creciente malestar. Se interrumpe aquí la acción principal con la salida de Belisa y Flora, que lamentan los desdenes de Borja y declaman retóricas resoluciones de rendirle, y de la Virtud, que las conmina a desistir. Sigue una serie de escenas cortas en que se entretejen los avances de Belisa y Flora con el rápido proceso de la enfermedad de la Emperatriz. Y llegado el fatal desenlace, incumbe a Borja dar la noticia del fallecimiento al Rey. Carlos la recibe con profunda resignación y comisiona al Duque para que conduzca el cadáver a Granada. Nueva interrupción de Belisa y Flora, en tuna escena de billetes amorosos cambiados por Sansón, que sirve en parte como descanso dramático a las escenas culminantes del acto: la entrega de los despojos mortales de la Emperatriz, horriblemente descompuestos, la violenta impresión que esto causa al Duque, y su determinación de buscar refugio en la vida religiosa.

En el acto segundo se esboza la actuación de Borja como Virrey de Cataluña, intercalando la historia de Rocafort, jefe de bandoleros a quien el Duque apresa y condena, y mezclando varias escenas cómicas en que descuellan Sansón, disfrazado de mujer, y Belisa, disfrazada de paje. Al final del acto llega un emisario con permiso de Carlos V para.que Borja se retire a Gandía. De nuevo reitera éste su determinación de alejarse del "mundo y sus ambiciones" si sobrevive a su esposa, y se concluye el acto con el anticipo de la muerte de Leonor de Castro.

En el tercer acto, viudo ya el Duque, decide profesar en la Compañía de Jesús, y va a Roma a poner su vida a las órdenes de San Ignacio. Carlos V, deseoso también de abandonar el mundo y sus engaños, comunica a su hijo Felipe la impostergable decisión de retirarse a Yuste. Llega don Gaspar de Villalonio con pliegos de Borja para Su Majestad en los que impetra licencia para entrar de religioso. Concedida ésta, comienza el santo su noviciado en Oñate, en compañía de su hijo Juan y el inseparable Sansón. UItimas intervenciones de Flora y Belisa, a quienes Sansón desengaña explicándoles la burla de los billetes trocados. Y trenzadas con esas cómicas escenas, otras en que Borja, 'con humildad y devoción ejemplares, realiza bajos quehaceres y se sobrepone a la tentación de 
aspirar a la mitra pontificia. En la escena final, un ángel congratula a la Compañía y anuncia la futura actuación del santo, y ésta, agradecida, acepta los parabienes y dedica la comedia al Virrey visitante.

De los tres actos de esta comedia, es el primero el que nos parece de más limpia dramaticidad y más feliz expresión poética, especialmente las escenas relacionadas con la muerte de la Emperatriz. Por ejemplo, al recibir Carlos la infausta nueva, expresa su resignación en la tersa sobriedad de estos versos:

Llevó Dios lo que era suyo, Su voluntad obedezco:

Dios la đió, Dios la quitó;

a su querer me sujeto.

(Acto I, versos 752-755.)

$\mathrm{Y}$, cuando en el pisodio del acto de la entrega del cadáver de la Emperatriz, aparece éste horriblemente descompuesto, exclama el Arzobispo:

¿Qué materia hay aquí de un desengaño!

$\mathrm{Y}$ Borja, profundamente conmovido por la escena que cambiaría el rumbo de su vida:

¿Que aquí paró tan verde primavera!

No más servir señor que se me muera.

Herido estoy, mi Dios, y arrepentido

de lo mal que he vivido.

Oh, quién naciera agora

para no malograr sólo una hora!

¡Oh, quién siempre trajera

presente el rostro de la muerte fiera!

iOh, si rompiera tanto loco enredo,

ya que no vuestro amor, siquiera el miedo

que aquí para la pompa lisonjera!

No más servir señor que se me muera.

( $\mathrm{I}, 1108-1119$.

E idos todos, queda Borja solo dando expresión a sus meditaciones

-verdadera meditatio mortis - en estas décimas con que termina el acto:

Imperios, ¿̇en qué estribáis?

Tronos, ¿ sobre qué os tenéis? 
Majestad, ¿de qué pendéis?

Grandezas, ¿a qué aspiráis?

¿De qué sirve que creais

la pompa que el mundo admira

si tan fácilmente expira

el trono y la majestad?

Sólo la muerte es verdad

que lo demás es mentira.

Hermosura, ¿qué te has hecho?

Beldad, ¿dónde te escondiste?

Salud, ¿cómo te perdiste?

Vida, ¿ cómo te has deshecho?

Lozanía, ¿qué provecho

conserva su lucimiento

si eres flor expuesta al viento,

si rosa eres bella y roja

que a un embate se deshoja

y se marchita a un aliento?

¿Qué locura es, qué locura

la de los necios engaños,

si los más floridos años

dan en una sepultura?

Girasol, ¿ cuánto te dura

beberte del sol el rayo,

si llega un mortal desmayo

cuando se ausenta su coche, y acaba sola una noche

los lucimientos de un mayo?

¿Qué importa que de tus galas,

oh pajarilo, presumas?

¿Qué importa, nave de plumas, que peinen luces tus alas, si hay en los cañones balas con que romperte las velas, $\mathrm{y}$ al tiro que no recelas, sesgando el aire sereno, te interrumpe sólo un trueno

la presunción con que vuelas?

Arroyuelo, ¿a dónde vas? ¿Donde corres, arroyuelo?

Mira no te encutentre un hielo que a tu pesar pararás.

O al menos, si corres más 
hasta el mar, anegaraste, y si a sus ondas llegaste, tủ mismo tu muerte fuiste, pues más temprano moriste cuando más te apresuraste.

Pues si a girasol aspiro, ¿ cómo no temo una helada?

Si soy ave remontada, ¿ cómo no recelo un tiro? Si dulce arroyo me miro, ¿quién me podrá ser apoyo para no hundirme en el hoyo, que es como el mar de la muerte, acabando de una suerte hombre, flor, ave y arroyo?

(I, 1124-1183.)

Fácil es percibir en estas bellas décimas recolectivas el influjo formal del soliloquio de Segismundo en la primera jornada de $L a$ vida es sueño, cuya primera edición es de 1636. Pero ese influjo no basta para explicar la delicada factura, la densidad de pensamiento y el tono casi bíblico de este otro lírico soliloquio. Además, se reconocerá inmediatamente la identidad esencial entre ellas y la Canción a la vista de un desengaño. La insospechada celeridad con que la Muerte, tocando con su ala helada la fresca belleza de la Emperatriz, da tema al desengaño del Duque, es la misma con que un halcón, acallanđo para siempre el libre canto de un jilguerillo, desengaña al religioso de la Canción. ¿ No habrá sido, entonces, el antológico poema una reelaboración del fin del acto primero de la comedia ? ${ }^{20}$

Citemos, para tener más cabal idea de la pieza, pasajes de índole diferente. Véanse, en los dos que siguen, reflejos del humorismo apicarado y sabihondo del gracioso, en contraste con la noble gravedad del protagonista. Sansón, en la escena de la caza, se burla de tanto ajetreo por ir detrás de una simple grulla, y se entabla el siguiente diálogo:

Sansón. Sin salir pie de tu casa, hay en los naipes halcones que te cacen mil doblones con solamente una basa. 
Borja. No, que perder no es prudencia, del juego entre la inquietud, con el tiempo la quietud y el dinero y la conciencia.

Sansón. Enamora.

Borja.

No es valor

por sola una liviandad

sujetar la voluntad

a esclavitudes de amor.

Sansón. Pues ¿para qué te casaste, $o$, por huír tanto daño, por qué no fuiste ermitaño o religioso te entraste?

Borja. Es nuestra vida, Sansón, una comedia de estado, y hago el papel que me han dado de su representación.

De casado represento en la jornada primera.

Sansón. Es decir, que no hay tercera, pues se hizo ya el casamiento.

Borja.' No sé ahora lo que resta de mi vida en adelante.

Sansón. Si de ella eres comediante, te has de casar cada fiesta; mudar trajes, ir de noche, echar versos a un balcón, soneto a la dilación, de acá soto vuelve el coche.

A cada guante, un conceto;

a cada caso, un billete; y hacerme a mí el alcahuete, porque hago el papel faceto.

$$
\text { (I, 49-84.) }
$$

La misma veta jocunda de mofarse de las fórmulas teatrales y de ver la vida por su lado flaco reaparece en el parlamento en el cual Sansón parodia el estilo sentencioso en que conversan Duque y Emperador. Carlos V discurre sobre cuánto más fácil es gobernar 
fieras que hombres, indicando como ejemplos reiterativos "al ave, al pez, al toro y al caballo", a lo que replica Borja:

Borja. Del ave lo altanero, del pez lo fugitivo y lo ligero, lo bravo de la fiera, lo arriscado del toro en la barrera, del caballo alentado 1o atrevido, resuelto $\mathrm{y}$ desbocado, pues si de tales cosas el abismo las junta el hombre en un sujeto mismo, ¿qué mucho que regirle sea más grave que no al caballo, al toro, al pez y al ave?

$$
\text { (I, 161-170.) }
$$

Y entonces Sansón, echando también su cuarto a espadas:

Sansóri. Señor, con tu licencia también diré mi poco de sentencia; y a darla un dicho de mi amo media, que dice que vivimos de comedia, y tiene la comedia, entre otras leyes, que hablen los lacayos con los reyes.

Carlos. Yo aquesa opinión sigo. Dí en buen hora, Sansón.

Sansón. que en gobierno de imperios absolutos, más fácil que hombres se gobiernan brutos, porque aunque penas mil se les recrezcan, no supierón jamás lo que se pescan.

Si el ave es una boba, cuando el azor la roba; si es un vinagre pez tan majadero, que él mismo se barrena el tragadero; si con tener el toro arma tan cierta se deja atar, como una mosca muerta; si para sujètallo una manta mojada es el caballo del freno a la molestia, y se deja ensillar como una bestia : eso es porque les falta entendimiento, y no saben más [cosas] que un jumento. Pero el hombre aprehende, y al más prudente rey se las entiende, 
ni es fácil enfrenallo, como al necio caballo; ni hacerle aleve robo, como al pájaro bobo; ni amarrarle a las leyes como al yugo los bueyes; ni echarle a su peligro capa o velo, que a pescado que entiende no hay anzuelo; $y$ con tener los hombres tantos males, no hay quien pretenda ser rey de animales; y regirlos se tiene en más decoro, que no al caballo, al ave, al pez y al toro.

$$
\text { (I, 171-208.) }
$$

Para dejar muestra de un pasaje de tipo narrativo, señalemos uno en que la Emperatriz refiere a Leonor su ominoso sueño. Nótese en él como, en total contraste con el ingenioso gracejo de Sansón, se va perfilando con pinceladas cada vez más tétricas la figura sañosa de la Parca

que en ampolleta de huesos

las horas registra en polvo.

También, la serie de metáforas visuales --matar la luz, agostar el verdor, deslavar la grana, empañar el cristal- con que se anticipa reiteradamente el infausto efecto de la acción de Atropos:

Emperatriz. Soñaba que estando Cloto ministrando de mi vida los nobles hilos de oro, y Laquesis en la urdimbre sutil de mis años pocos, llegaba la fiera hermana, la del esqueleto tronco, la muda estatuia de mármol, la del aspecto sañoso, la rigurosa medida de tiempos largos y cortos que en ampolleta de huesos las horas registra en polvo, y abriendo de su tijera los dos filos rìgurosos, a cortar iba la estambre de mi edad (lance forzoso). 


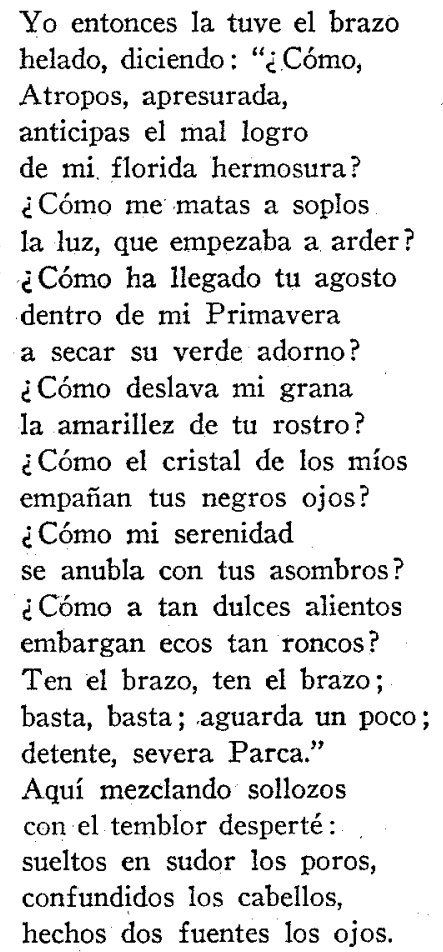

(I, 268-310.)

Estos pasajes, citados por la variedad de su contenido, evidencian la soltura con que manejaba Bocanegra el verso, la multiplicidad de formas métricas que empleaba y los novedosos efectos que lograba aun dentro de una estética ya anquilosada.

Hay, además, ciertos pormenores de la representación que tal vez interesen tanto al literato deseoso de ahondar en la historia de nuestra lírica y nuestro teatro como al investigador de nuestros procesos culturales. Se inició el acto con una loa - pedantísima, por cierto- escrita en seis octavas reales y un soneto. Dividieron las jornadas "un entremés en negro y dos danzas de niños estudiantes de lo más noble de México." Y se dió fin a la comedia

con un mitote o tocotín, danza majestuosa y grave hecha a la usanza de los indios, entre diez $y$ seis agraciados niños, tan vistosamente adornados con preciosas tilmas y trajes de lama de 
oro, catles, o coturnos bordados de pedrería, copiles, o diademas sembradas de perlas y diamantes, quetzales de plumería verde sobre los hombros, que sólo esta danza y su lucimiento bastara para desempeño del festejo más prevenido.

$\mathrm{Y}$ al son de instrumentos indígenas - ayacatztles "que son unas curiosas calabacillas llenas de guijas" y un teponatztle- se cantaron eatorce coplas escritas para la ocasión por el estilo de las siguientes:

Salí, mexicanos, bailá el tocotín, que el sol de Villena tenéis en zenith.

En vuestra Laguna la rosa y jazmín ya le acreditaron de idalio pensil.

Las crespas alcobas del Lago sutil son a sus aspectos celeste zafir.

De vutestras campiñas

el verde tabí da espigas de oro por tosco maíz.

Salí, mexicanos, bailá el tocotín, que el sol de Villena tenéis en zenith.

La importancia de que el entremés fuera de negros, y que el espectáculo final tuviera un subido matiz indígena no puede escapar a los que saben que ni nuestra cultura, ni las artes que florecen dentro de ella, son exclusivamente europeas. El hecho de que se bailara un tocotín ante un encopetado virrey, por los hijos de los más encopetados vecinos de la sede virreinal, es prueba insoslayable de que no se había olvidado en Nueva España la lección de los humildes frailes que un siglo antes hicieron representar a sus neófitos indígenas autos esencialmente mestizos. Esa lección, mantenida en 
los coloquios de González de Eslava a fines del siglo xvi y repetida en 1620 por Francisco Bramón en su Auto del triunfo de la Virgen, es la que aparece ahora en Bocanegra y aparecerá de nuevo en los gráciles tocotines de Sor Juana. Hasta por los intersticios del formulismo barroco se deslizaba suavemente el aroma de la tierra americana.

En resumen, con todo lo que va citado se ve el firme dominio del verso y el notable don lírico que individualizan esta comedia. Tiene - como al fin producto de su époća- esa irrestañable riqueza expresiva que al proliferar en abundantes pormenores reiterativos a veces agobia al lector moderno. Por lo demás, características del barroco son también esa desazón ante la vida, ese melancólico cavilar sobre el hombre y su destino y la constante aspiración a trocar las engañosas vanidades de un mundo caduco por la seguridad de un bien morir. Tal ideología, que impulsa a Carlos $\mathrm{V}$ a recogerse en Yuste y al Duque de Gandía a tomar el hábito, es la misma que trasciende de la obra de Quevedo o de Calderón, se hace pétrea aspiración de infinito en El Escorial y ascensionales formas polícromas en las telas del Greco. Si por la misma ruta van, haciendo eco al mismo cavilar, los versos conmovidos del jesuita mexicano, es prueba de que aquende el Atlántico resonaban sincrónicamente las mismas vibraciones culturales. $\mathrm{Y}$ como, además, se matiza esa comedia con voces, ritmos y multicolores vestuarios de acá, resulta en conjunto un espectáculo a la vez español y americano, de innegables méritos literarios y culturales. Por todas las razones expuestas habrá que contar, de ahora en adelante, con la pieza de Bocanegra tanto al historiar las letras coloniales como al seguir la trayectoria del pensamiento que las hizo cristalizar.

José JUAN ARrom, Yale University. 
P. MATIAS DE BOCANEGRA, S. J.

(1612-1668)

Canción a la vista de un desengaño

Una tarde en que el Mayo

de competencias quiso hacer ensayo, retratando en el suelo

las bizarrías de que se viste el cielo, sin recelar cobarde

que en semejante alarde

pudiera ser vencido, rico, soberbio, ufano y presumido;

cuando el Sol al poniente

con luz incandescente

rodaba al horizonte

- despeñado Faetonte

de su ardiente carroza-

a sepultarse en túmulos de rosa,

sale a vistas un Prado

de flores estrellado

con tanta lozanía, que reta y desafía

a competir con ellas

a cuantas brillan en el globo Estrellas.

Por centinela agrega

aquesta hermosa vega

un Monte, de esmeralda

desde la cima a la espaciosa falda:

cual Argos se introduce

con blancas azucenas con que luce:

arriscado gigante,

del Cielo inculto Atlante,

Polifemo eminente

que las nubes abolla con la frente,

en cuya cresta altiva

nace una Fuente viva.

$\mathrm{Y}$ no hallando descanso

en la estrecha prisión de su remanso,

la Fuente cristalina

sus arenas trasmina

y astuta se desata

en hilos de cristal, venas de plata, 
hasta que despechada

-la cárcel quebrantadadesde la altiva peña

cual Icaro de nieve se despeña, corriendo a poco trecho

-sierpe de vidrio- al Monte por el pecho.

Llega a la falda hermosa,

y jueguetón retoza

con mirtos $\mathrm{y}$ alhelíes,

recamando de perlas sus rubíes;

y el Prado, que se bebe

en liquidos cristales tanta nieve,

con más flores se enriza,

más vario se matiza,

tributándole en flores

cuantos al Río le bebió licores.

Esta riqueza viste

el Prado, cuando triste

-de miedos abrumado,

el corazón en ansias anegado-

a un mirador salía

un Religioso que ya no podía

a si mismo sufrirse,

según siente de penas combatirse:

los ojos arrasados,

los pulsos ahogados,

pausados los alientos

$y$ en tumulto civil los pensamientos.

Al monte y la campiña

la vista extiende, a ver cómo se aliña,

por ver si así sosiega

de sus discursos la interior refriega.

Suspensos los sentidos,

del todo embebecidos,

de lo que mira el Religioso vive;

porque allí no percibe

otra cosa que el monte y la campaña

que dulcemente su dolor engaña,

-cesando los tropeles

y aflojando a la pena los cordeles,

cuando el viento se calma

que levantó la tempestad del alma-,

hasta que le despierta

de aquella vida muerta 
un músico Jilguero,

de su quietud agüero.

Sentóse en un pimpollo

de un sauce - verde escollo-,

$\mathrm{y}$ en alto contrapunto,

tomando por asunto

sus amores y celos,

suspendió con su música a los Cielos.

Calle la melodía

con que el Tracio las fieras suspendía;

allánese el acento

con que a las piedras daba movimiento

el de Anfión süave;

cese el concento grave

con que Arión cantaba

y a los ariscos peces enlazaba:

que el Jilguero pudiera

detener a Faetón en su carrera,

si del flamante azote los traquidos

le permitieran concederle oŕdos.

Las flores, que le vieron, común aplauso hicieron,

a su voz se callaron

y algunas para verle se empinaton;

el arroyo ruidoso

se detuvo impetuoso,

đejó atrás su corriente

-si animado cristal, hielo viviente-.

$\mathrm{y}$ a sus pasos veloces

fué rémora el oír tan dulces voces.

Interpolaba el canto

el músico Jilguero, y entre tanto,

libre, gozoso y rico,

las alas se peinaba con el pico:

eriza como espuma

la matizada pluma,

en cuyos tornasoles

envidia tuvo el Sol a muchos soles.

Segunda vez entona

la voz de que blasona,

dejando sus canciones

al hemisferio todo en suspensiones,

y más que suspendido

al lloroso afligido, 
cuya infelice suerte esquiva, le convierte toda aquella dulzura en venenoso cáliz de amargura.

$\mathrm{Y}$ así, con un despecho el corazón deshecho en lágrimas fervientes que manan de sus ojos las dos fuentes, al Jilguero mirando -su libertad dichosa contemplando:de esta suerte le dice:

"Avecilla felice que dulcemente cantas en alcándaras de esas verdes plantas: yo peno, tú te ríes, yo me quebranto cuando tú te engríes; por eso tú te ríes y yo peno, porque estás de mis penas muy ajeno, porque tengo en esposas la libertad, Jilguero, que tú gozas. i Ah, libertad amada, en mis floridos años malograda!

A fe, amigo Jilguero, que en la jaula no fueras tan pariero, pues sus penas atroces anudaran tus voces; prisionero, lloraras la libertad perdida, y no cantaras. Afuera confusiones; del alma cesen ya las turbaciones: $¿$ de qué me asusta el miedo, si en el siglo también salvarme puedo?

"Si en cuna de cristales nace el Arroyo, y busca sus raudales, hallando su destino entre tiscos camino, a despecho de peñas y ribazos, buscando libertad hecho pedazos; si del verde capullo rompe la Rosa con vistoso orgullo la trinchera espinosa, por salir a campear la más hermosa; aunque el nacer temprana le sea presagio de morir mañana; 
si el $\mathrm{Pez}$, sin viento alguno

entre las crespas ondas de Neptuno,

su gusto no le impide

la tempestad que sus espácios mide,

de orilla a orilla aporta

y -escamado bajel- los mares corta:

¿cómo yo en cautiverio

tengo mi libertad, siendo mi imperio

tan libre, que no hay fuerza

que lo limite o tuerza?

Cielos, ¿ en qué ley cabe

que el Arroyo, la Rosa, el Pez y el Ave,

que sujetos nacieron,

gocen la libertad que no les dieron,

y yo (iqué desvarío!)

naciendo libre, esté sin albedrío?"

Aquesto discurría,

y ya se resolvía

-ciego y desesperado-

a renunciar el religioso estado,

cuando vió que volando,

los aires fatigando,

un Neblí se presenta,

-Pirata que de robos se sustenta,

emplumada saeta,

errante exhalación, veloz cometa-.

De garras bien armado,

el alfanje del pico acicalado,

pone a su curso espuelas

desplegando del cuerpo las dos velas.

Bajel de pluma, sube

hasta las nubes por fingirse nube,

desde donde - mirando

al Jilguero cantando

gustoso y descuidado,

de riesgos olvidado-

el Neblí se prepara

y rayo de las nubes se dispara,

con tan sordo tronido

que sólo fué sentido

del Ave, que asustada

se vido entre sus garras destrozada

$\tan$ impensadamente,

que acabó juntamente

la canción y la vida, 
dando el último acento por la herida, dejando con su muerte tan funesta de mil asombros llena la floresta, que llora lastimada su inocencia ofendida y agraviada.

Aquí, lleno de horrores y de nuevos temores, confuso el Religioso, penitente, lloroso, con el suceso extraño conociendo la causa de su daño, $\mathrm{y}$ en lágrimas bañado que del dolor la fuerza le ha sacado, desiste de su intento -alumbrado de Dios su entendimiento-, y para prepararse, de esta suerte comienza a predicarse:

"Contempla la libertad, Alma, que ciega apeteces, porque en negocio tan grave no es bien de ignorancia peques.

En un difunto Jilguero tus dèsengaños advierte, y pues te engañó su vida, desengáñete su muerte.

Si en la prisión de una jaula el pajarillo estuviese, aunque le viera, no osara el Gerifalte prenderle.

Muere porque libre vive; luego la razón es fuerte: cautiva el Ave se gana, luego por libre se pierde.

Que si en el campo el Arroyo libre no anduviera siempre, no probara el precipicio a donde van sus corrientes;

y si del mar las anchuras libre no midiera el Pece, tampoco incauto perdiera la libertad en las redes. 
Que aunque en la vega la Rosa

libre de espinas campee,

o de la mano atrevida

o del bruto bien se teme;

y a tantos riesgos sujeta

se mira el Ave, aunque vuele, cuantos Corsarios astutos la asaltan y la acometen.

Si el Arroyo, el Pez, el Ave, la Rosa, por libres mueren, en Pez, en Ave, en Arroyo y en Rosa es bien que escarmientes.

Que si preso me gano, de voluntad a la prisión me allano; y si libre me pierdo, no quiero libertad tan sin acuerdo!"

\section{$\mathrm{N} O \mathrm{TAS}$}

1 José Mariano Beristáin y Souza, Biblioteca hispano-americana septentrional ... $2^{4}$ ed. Amecameca, 1883, I, 179.

2 Francisco Zambrano, S. J., La Compañia de Jesús en Méxiro. México, 1939, p. 96 y Alfonso Méndez Plancarte, Poetas novohispanos, seyundo siglo (1621-1721). México, 1944, xlix-li y lxxv, nota 43.

3 Luis González Obregón, D. Guillén de Lampart, la Inquisición y la Independencia en el siglo XVII. París, México, 1908, p. 197.

4 José Toribio Medina, La imprenta en México (1539-1821). Santiago de Chile, 1907, II, pp. 197-333, números 535, 553, 664, 666, 675, 680, 681, 702, 765, 812, 842. También Beristáin, op. cit.

5 Marcelino Menéndez y Pelayo, Historia de la poesía hispano-americana, I. Madrid, 1911, pp. 68-70 y Beristáin, op. cit., I, 104; Ir, 346; III, 221 y IV, 40 .

6 Antonio Castro Leal, Las cien mejores poesías (líricas) mexicanas, $3^{\text {\# }}$ ed. México, 1945, 11-20.

7 Francisco Pimentel, Historia de la literatura y de las ciencias en México. México, 1885, pp. 125-127.

8 Loc. cit, p. 68. 
9 Julio Jiménez Rueda, Historia de la literatura mexicana. México, 1928, p. 71.

10 Carlos González Peña, Historia de la literatura mexicana. México, 1928 , p. 160.

11 Francisco González de Cossío, La imprenta en México, 1594-1820; cien adiciones a la obra de don José Toribio Medina. México, 1947.

12 Francisco Monterde, Bibliografia del teatro en México. México, 1933, p. 88 .

13 Revista de literatura mexicana, I, 1940, p. 166.

14 Julio Jiménez Rucda, ed. Sufrir para merecer. (Boletín del Archivo General de la Nación), xx, núm. 3, julio, sept., 1949, pp. 379-459.

15: Notables casos de este que pudiéramos llamar sofisma de atribución por contigüidad son la adjudicación del soneto "No me mueve, mi Dios, para quererte..." a fray Miguel de Guevara, (Vid. Marcel Bataillon, "El anónimo del soneto 'No me mueve, mi Dios...'" Nueva Revista de Filología Hispánica, Iv, 1950, pp. 254-269), y la del titulado "La ilusión", del cubano Manuel de Zequeira y Arango, al argentino Claudio Mamerto Cuenca. (Vid. mis Estudios de literatura hispanoamericana. La Habana, 1950, pp. 94-100).

16 En primer lugar, no existe ninguna semejanza en el tono, el estilo o la versificación de la comedia firmada por Bocanegra con los de Sufrir para merecer. Mientras la primera es, como adelante se verá, una pieza de grave intención y cuidada forma, Sufrir para merecer es superficial y desaliñada. Mientras en aquélla hay muy pocos apartes, y acción y diálogo son generalmente directos, esta otra está plagada de apartes, y tanto el argumento como su expresión son confusos y sumamente artificiosos. Mientras en la obra que damos a conocer no faltan momentos poéticos de hondo lirismo, en esta otra no se les encuentra por ninguna parte y en su lugar abundan la hojarasca de insinceras expresiones amorosas y la ruidosa piroctenia de celos que a nadie queman y ni siquiera deslumbran. La versificación misma, variadísima en Bocanegra - redondillas, romances, liras, décimas, octavas reales, sonetos, coplas - no puede ser más monótona en el autor de Sufrir para merecer, pues está casi toda versificada en romances y redondillas. En fin, el único verso en que el anónimo autor da señales de haber conocido la Canción de Bocanegra, le sirve sólo para un juego de palabras cuya pobreza expresiva y ausencia de. sentimiento podrá juzgar el lector:

Laura. Quiero olvidar y me pierdo

a vista de un desengaño, porque en tan crecido daño el desengaño me acaba.

$$
\text { (II, 1, p. 410.) }
$$


17 Medina, op. cit., p. 197, núm. 535. Allí mismo enumera Medina una docena de bibliografías donde se consigna la misma obra.

18 Para facilitar al lector que pueda seguir ésta y otras comparaciones entre la comedia y la canción, se ofrece el poema como apéndice a este trabajo.

19 Los hechos dramatizados de la vida del santo eran tan recientes $y$ bien conocidos, especialmente entre los miembros de la Compañía, como para no necesitar grandes búsquedas de parte de Bocanegra al armar la estructura biográfica. De todos modos, existía ya un importante tratado sobre dicho asunto: la Vida del P. Francisco de Borja, de Pedro de Ribadeneyra, S. J., publicada en Madrid en 1592. Es lógico suponer que no le fuera desconocida al sabio jesuíta mexicano.

20 Aunque sabemos a ciencia cierta que la comedia se estrenó en 1640, se ignora la fecha de composición de la Canción. Las reimpresiones más antiguas conocidas por Menéndez y Pelayo datan de 1775 y 1782 (op. cit., p. 68), e investigador tan familiarizado con la bibliografía de aquella época como Méndez Plancarte declara que tampoco conoce la edición primitiva ( $o p$. cit., p. 100). Ahora bien, el hecho de que en 1652 apareciera, como ya dijimos, la primera de las imitaciones conocidas de la Canción, nos permite fijar su composición antes de dicho año. La circunstancia de que las décimas fueran indispensable y lógica consecuencia de la acción de la comedia, y que, una vez conocidas, el éxito de ellas debió ser inmediato, nos lleva a conjeturar que el soliloquio incitara a escribir la canción y no a la inversa. E's, empero, pura conjetura. 
